Belenichev I.F., Gorchakova N.O., Bukhtiyarova N.V., Samura I.B., Savchenko N.V., Nefedov O.O., Bak P.G. Modulation of HSP70dependent mechanisms of endogenous neuroprotection with selenium derivatives under conditions of ischemic-type acute cerebrovascular accident modeling. Pedagogy and Psychology of Sport. 2020;6(4):99-108. elSSN 2450-6605. DOI http://dx.doi.org/10.12775/PPS.2020.06.04.009

https://apcz.umk.pl/czasopisma/index.php/PPS/article/view/PPS.2020.06.04.009

https://zenodo.org/record/4301432

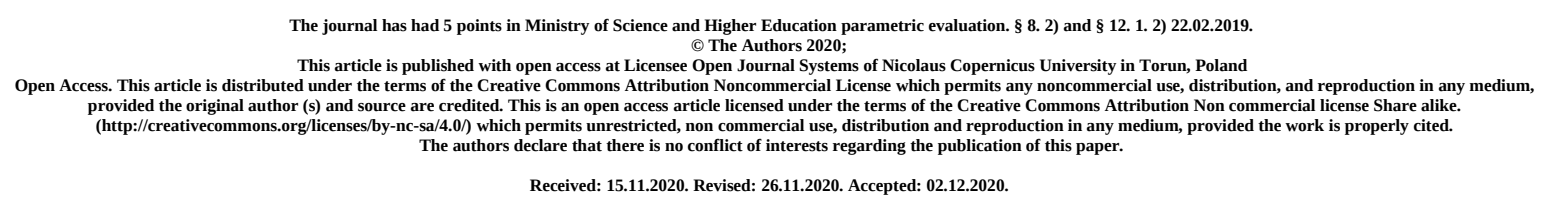

Received: 15.11.2020. Revised: 26.11.2020. Accepted: 02.12.2020.

\title{
Modulation of HSP70-dependent mechanisms of endogenous neuroprotection with selenium derivatives under conditions of ischemic- type acute cerebrovascular accident modeling
}

\author{
Belenichev I.F. ${ }^{1}$, Gorchakova N.O. ${ }^{2}$, Bukhtiyarova N.V. ${ }^{1}$, Samura I.B. ${ }^{1}$, \\ Savchenko N.V. ${ }^{2}$, Nefedov O.O. ${ }^{3}$, Bak P.G. ${ }^{1}$
}

Zaporizhzhia State Medical University of Health Ministry of Ukraine, Zaporizhzhia, Ukraine ${ }^{1}$ Bogomolets National Medical UniversityKyiv, Ukraine ${ }^{2}$

SE «Dnipropetrovsk Medical Academy of Health Ministry of Ukraine», Dnipro, Ukraine ${ }^{3}$

\begin{abstract}
The influence of selenium derivatives selenoline, cysteine selenate, and methionine selenate on the main indicators of HSP70-dependent mechanisms of endogenous neuroprotection under conditions of acute cerebrovascular accident (CVA) modeling has been investigated, and pathogenetic substantiation of prospects for their further study as potential neuroprotectors has been given. The experiments have been performed on white Wistar rats by bilateral irreversible ligation of the common carotid artery. Cysteine selenite and methionine selenite at a dose of $30 \mu \mathrm{g} / \mathrm{kg}$, and selenoline at a dose of $50 \mu \mathrm{g} / \mathrm{kg}$ were introduced intraperitoneally to the experimental animals once-daily for 4 days. Every day for 4 days, the severity of neurological reactions was assessed in points on a stroke-index scale, and the mortality rate in animals was recorded. In the process of biochemical studies of brain tissue, the state of mRNA expression, HSP70 level, hypoxia-induced factors (HIF) - HIF1 $\alpha$ and HIF-3 $\alpha$ were evaluated using the method of polymerase chain reaction (PCR) with realtime reverse transcription. While false-operated animals developed mild neurological disorders, the control group developed bilateral ptosis, circling movements, paresis and paralysis of the limbs. On the 4th day the mean score on Stroke-index P. McGraw neurological deficit assessment scale was $16.7 \pm 0.52$, and $40 \%$ of animals survived. In the cytosol and mitochondria of brain tissues, a decrease in HSP70 was detected by $47 \%$ and $59 \%$, respectively. The administration of selenite cysteine, selenite methionine and selenoline contributed to the normalization of this indicator, to a greater extent under the action of selenite cysteine. In the control group there was a decrease in HSP70 mRNA expression. After administration of all the studied compounds, a tendency to increase the expression of HSP70 mRNA was observed compared to the controls. Under conditions of cerebral circulation insufficiency ACCI, in brain tissue, a decrease in the synthesis of HIF-1 $\alpha$ at the
\end{abstract}


stage of translation with ATP deficiency was noted. The course administration of seleniumcontaining drugs to rats with ACCI induced an increase in HIF1 $\alpha$ levels: cysteine selenite by 11.2 times, selenite methionine - by 3.13 times, and selenoline - by 1.1 times ( $>00.05)$. A significant difference in relation to the expression of HIF-3 $\alpha$ was shown only after administration of cysteine selenite (by 4.3 times higher than the control). The study of antioxidant modulation of HSP70-dependent mechanisms of endogenous neuroprotection of the brain have demonstrated that administration of selenium-containing medications cysteine selenite, methionine selenite, and selenoline lead to a decrease in neurological signs and the mortality rate in animals with ACCI. The action of selenium-containing drugs is realized due to their positive influence on the glutathione system, the preservation of energy-producing function of organs and mitoprotective effect. The obtained results indicate the relevance of further study of selenium-containing drugs on other models of pathological processes accompanied by ischemia.

\section{Key words: selenium derivatives, HSP70, dependent mechanisms, neuroprotection, acute cerebrovascular accident}

Despite significant advances in the prevention and management of acute cerebrovascular accident (CVA), the issue continues to be of extreme medical and social importance [2, 10]. Stroke is the second leading cause of death and the leading cause of disability among the residents of Ukraine, creating a serious burden for the healthcare system, the economy and society as a whole [2].

Clinical research studies over the past 15 years have indicated the positive effects associated with the administration of primary and secondary neuroprotectors in the treatment of ischemic stroke [2-5, 10]. However, basic neuroprotective agents do not always produce the expected therapeutic effect in the acute phase of cerebral stroke [14].

In this regard, in order to optimize basic therapy, it is justified to identify new molecular therapeutic targets of ischemic neurodestruction and to search for medications that selectively modulate them. Therefore, studies of molecular-biochemical brain damage in CVA and the development of new approaches to targeted neuroprotection, the most promising targets of which are considered to be strengthening the mechanisms of endogenous neuroprotection and neuroplasticity, in particular, the coupled glutathione reduced/heat shock protein 70 (GSH/HSP70) system [1, 6-7, 11].

The glutathione unit of the thiol-disulfide system of the brain plays a significant role in the mechanisms of endogenous neuroprotection [3]. Recent studies in the field of neurochemistry and neuropharmacology have established that glutathione is not only the main component of the antioxidant defense of the neuron, improving its resistance under ischemic conditions, but is also a neurotransmitter and neuromodulator (in micromolar concentrations it is an agonist of glutamate receptors; and in millimolar concentrations it modulates $\mathrm{SH}-$ methyl-D-aspartate (NMDA) receptors, regulating endogenous neuroprotection links and neuroapoptosis [2]. Increasing the systemic glutathione levels by the use of modulators of glutathione synthesis is a modern strategy for replenishing glutathione deficiency in ischemic neurodestruction [2].

Of particular interest in this regard are selenium derivatives that affect the expression and activity of GSH-dependent enzymes and regulate glutathione levels [9]. The role of glutathione (GSH) in the regulation of HSP70-dependent mechanisms of endogenous 
neuroprotection is known [12, 13]. Thus, the search and development of methods for pharmacological modulation of GSH/HSP70-dependent mechanisms of endogenous neuroprotection is an important and promising task of modern pharmacology. The foregoing theoretically substantiates the prospects for the study of selenium derivatives Selenolin (diacetophenonyl selenide), Se-methionine and Se-cysteine as neuroprotective agents [15].

The purpose of the study was to investigate the action of selenium-containing drugs Selenolin, Se-methionine and Se-cysteine on the main indicators of HSP70-dependent mechanisms of endogenous neuroprotection under conditions of experimental acute cerebral circulation insufficiency (ACCI) and to substantiate theoretically the prospects for their further study as promising neuroprotectors.

\section{MATERIALS AND METHODS OF RESEARCH}

The experimental part was performed on 100 white Wistar rats weighing 160-170 g collected from the breeding center of Institute of Pharmacology and Toxicology of the Academy of Medical Sciences of Ukraine. The experimental animals were kept in accordance with the sanitary and hygienic standards of the vivarium of ZSMU (air temperature $22 \pm 2{ }^{\circ} \mathrm{C}$ ) under conditions of a natural change of day and night, food and nutrition ad libitum. [9].

The experiments were carried out in accordance with the legislation of Ukraine, Commission on Bioethics and Pharmacy "General ethical animal experimentation" (Kyiv, 2001), the provisions of the European Convention "On Protection of Vertebrate Animals used for experimental or other scientific purposes” (Strasbourg, 1986; 1998) [2]. The experiments were conducted on the basis of the Scientific medical-laboratory center of ZSMU, certified by the Ministry of Health of Ukraine (certificate No. 039114). Compliance with ethical standards is confirmed by the Commission on Bioethics of ZSMU.

Acute cerebrovascular accident (CVA) in animals was performed by bilateral irreversible occlusion of the common carotid artery (CCA) under thiopental anesthesia (40 mg $/ \mathrm{kg}$ ) [8]. Every day for 4 days (acute period of cerebral ischemia), the severity of neurological disorders was assessed in points on Stroke-index P. McGraw neurological deficit assessment scale [2, 8], and mortality rate in all the experimental groups was calculated.

To study the influence of selenium-containing drugs on HIF1 $\alpha$ levels and severity of neurological signs in rats with ACCI, separate groups (20 rats in each group) of animals were administered: L-Se-cysteine (Sigma Aldrich, USA) at a dose of $30 \mu \mathrm{g} / \mathrm{kg}$, L-Se-methionine (Sigma Aldrich, USA) $30 \mu \mathrm{g} / \mathrm{kg}$ [9], and Selenoline (JSC "Bioamide", Russia) 50 $\mathrm{kg} / \mathrm{kg}$ [9] during the observation period (4 days). The drugs were administered intraperitoneally once a day.

False-operated and control animals were administered intraperitoneally physiological solution throughout the study.

For biochemical studies, blood was quickly removed from the brain, then brain tissue was separated from the brain tunic, and the samples were placed in the liquid nitrogen. Then they were finely ground in liquid nitrogen to powders and homogenized in a 10-fold volume of a medium $\left(2^{\circ} \mathrm{C}\right)$ containing (in mmol): sucrose 250, Tris-HCl buffer 20, EDTA 1 (pH 7.4) [8]. At a temperature of $+4^{\circ} \mathrm{C}$, the mitochondrial fraction was isolated by the method of differential centrifugation on the refrigerator centrifuge Sigma 3-30k (Germany). To purify the mitochondrial fraction from large cell fragments, centrifugation was preliminarily carried out for $7 \mathrm{~min}$ at $1000 \mathrm{~g}$, and then the supernatant was re-centrifuged for $20 \mathrm{~min}$ at $17000 \mathrm{~g}$. The supernatant was decanted and stored at $-80^{\circ} \mathrm{C}$.

To assess the state of expression of HSP70 mRNA, hypoxia-induced factors (HIF) HIF$1 \alpha$ and HIF-3 $\alpha$, the method of polymerase chain reaction (PCR) with reverse transcription in real time (RT-PCR), the amplifier CFX96 ${ }^{\text {TM }}$ Real-Time PCR Detection Systems (Bio-Rad Laboratories, Inc., USA) were used. 
The content of HSP70, a protein in the brain tissues, was determined by Western blot analysis. Proteins were separated on a $10 \%$ polyacrylamide gel by electrophoresis. Primary antibodies against HSP70 (Santa Cruz Biotechnology) and secondary antibodies (biotinylated anti-mouse IgG, SIGMA, USA, cat. \# 051M4885) were used. For visualization, the membrane was treated with a solution of 3-amino-9-ethylcarbazole (Sigma, USA, cat. No. A6926). The HSP70 protein was detected using densitometry in the Adobe Photoshop program.

Statistical processing of scientific research data was carried out using the

STATISTICA ${ }^{\circledR}$ for Windows 6.0 software package (StatSoftInc., No. AXXR712D833214FAN5), as well as SPSS 16.0, Microsoft Office Excell 2003. Before applying statistical criteria, the hypothesis about the normal distribution of random variables was tested (using the Shapiro-Wilk and Kolmogorov-Smirnov tests). Under normal distribution conditions, the reliability of intergroup differences was determined using the experimental data obtained using the Student's parametric t-test. If the data did not correspond to the laws of normal distribution, a comparative analysis was carried out using the nonparametric Mann-Whitney U test.

For comparison of independent variables in more than two samples, analysis of variance (ANOVA) with normal distribution or the Kruskal-Wallis criterion for a distribution other than normal were used. To analyze the regularities of the relationship between different indicators, a correlation analysis was carried out using the Pearson or Spearman correlation coefficient. For all types of analysis, differences $p<0.05$ (95\%) were considered statistically significant.

\section{RESULTS AND DISCUSSION}

The assessments of the neurological status of animals on the McGraw scale showed that severe neurological disorders in the form of paresis and paralysis did not develop in the group of false-operated animals. Neurological soft signs in the form of sluggishness of movements were noted on the $1^{\text {st }}$ day of the experiment. Animals in the control group developed significant neurological disorders - bilateral ptosis, circling movements, paresis and paralysis of the limbs. On the $4^{\text {th }}$ day after surgery, the average P.McGraw score in this group was 16.7 \pm 0.52 . By the $4^{\text {th }}$ day, $40 \%$ of the animals survived in the control group. 
Table 1 - Influence of selenoline, Se-methionine, and Se-cysteine on neurological status according to the McGraw scale and mortality rate in animals with ACCI

\begin{tabular}{|c|c|c|c|c|c|c|}
\hline \multicolumn{2}{|l|}{ Indicators } & $\begin{array}{l}\text { false- } \\
\text { operated } \\
\text { animals }\end{array}$ & $\begin{array}{l}\text { Control } \\
\text { (ACCI) }\end{array}$ & $\begin{array}{l}\text { ACCI + } \\
\text { selenoline }\end{array}$ & $\begin{array}{l}\text { ACCI + } \\
\text { Se-methionine }\end{array}$ & $\begin{array}{l}\text { ACCI + } \\
\text { Se- cysteine }\end{array}$ \\
\hline $\begin{array}{l}\text { Index } \\
\text { McGraw }\end{array}$ & \multirow[b]{2}{*}{ 齐 } & $0,145 \pm 0,02$ & $10,2 \pm 0,47$ & $10,11 \pm 0,82$ & $10,12 \pm 0,72$ & $7,34 \pm 0,67$ \\
\hline $\begin{array}{l}\text { Mortality } \\
\text { rate }\end{array}$ & & 0 & 4 & 4 & 2 & 2 \\
\hline $\begin{array}{l}\text { Index } \\
\text { McGraw }\end{array}$ & \multirow[b]{2}{*}{ 胥 } & $0,043 \pm 0,02$ & $12,8 \pm 0,60$ & $10,31 \pm 0,57$ & $8,22 \pm 0,31 *$ & $7,7 \pm 0,24^{*}$ \\
\hline $\begin{array}{l}\text { Mortality } \\
\text { rate }\end{array}$ & & 0 & 6 & 1 & 2 & 1 \\
\hline $\begin{array}{l}\text { Index } \\
\text { McGraw }\end{array}$ & \multirow[b]{2}{*}{$\begin{array}{l}\vec{\theta} \\
m \\
m\end{array}$} & 0 & $14,5 \pm 0,50$ & $9,23 \pm 0,41 *$ & $8,0 \pm 0,27 *$ & $6,87 \pm 0,37 *$ \\
\hline $\begin{array}{l}\text { Mortality } \\
\text { rate }\end{array}$ & & 0 & 4 & 1 & 1 & 0 \\
\hline $\begin{array}{l}\text { Index } \\
\text { McGraw }\end{array}$ & \multirow[b]{2}{*}{ 离 } & 0 & $16,7 \pm 0,52$ & $8,27 \pm 0,27 *$ & $7,5 \pm 0,31 *$ & $5,65 \pm 0,22 *$ \\
\hline $\begin{array}{l}\text { Mortality } \\
\text { rate }\end{array}$ & & 0 & 4 & 0 & 0 & 0 \\
\hline $\begin{array}{l}\% \text { survi } \\
\text { animals } \\
\text { day/ } \\
\text { amount } \\
\end{array}$ & $\begin{array}{r}\text { ved } \\
4^{\text {th }} \\
\text { otal }\end{array}$ & $100 / 10$ & $40 / 30$ & $70 / 20$ & $75 / 20$ & $85 * / 20$ \\
\hline
\end{tabular}

Note: ${ }^{*}-\mathrm{p} \leq 0.05$ in relation to the control

Administration of selenium-containing drugs to animals with ACCI statistically significantly hampered the manifestation of neurological symptoms and decreased the mortality rate. Thus, rats treated with selenoline had a statistically significant decrease in the severity of neurological signs and symptoms on the $3^{\text {rd }}$ and $4^{\text {th }}$ days of stroke by 5.27 and 8.43 points respectively, in relation to the control group (Table 1). Animals that were administered selenoline had the mortality rate by30 \% less in comparison with the control group. The introduction of Se-methionine led to a significant decrease in neurological disorders on the $2^{\text {nd }}$ and $4^{\text {th }}$ days of ACCI by 9.2 and 4.58 points respectively, relative to the control $(\mathrm{p} \leq 0,05)$. Semethionine showed a $35 \%$ reduction of the death rate.

Se-cysteine was the most effective of the investigated selenium derivatives, its administration ensured a significant reduction of neurological disorders already by the end of the $2^{\text {nd }}$ day after stroke (by 5.1 points), and on the $4^{\text {th }}$ day it decreased by 11.05 points $(\mathrm{p} \leq 0,05)$, compared to the control group. Se-cysteine reduced mortality on the $4^{\text {th }}$ day of ACCI by $45 \%$.

There was a decrease in the levels of heat shock protein HSP70 in the brain tissue homogenate in every group of animals (Table 2).

Recently, the data about heat shock proteins cytoprotective and regulatory role in cerebral ischemia, accompanied by intensification of the processes of free radical proteins damage, a shift in the thiol-disulfide equilibrium, development of nitrosative stress, and glutamate excitotoxicity have found [13]. 
Table 2 - Levels of HSP 70 in the brain of animals with ACCI

\begin{tabular}{|l|l|l|}
\hline Group of animals & $\begin{array}{l}\text { HSP70 ,s.u./g } \\
\text { (cytosol) }\end{array}$ & $\begin{array}{l}\text { HSP70 , s.u./g } \\
\text { (mitochondria) }\end{array}$ \\
\hline False-operated & $15,9 \pm 0,82$ & $7,8 \pm 0,33$ \\
\hline ACCI & $6,5 \pm 0,46$ & $4,1 \pm 0,17$ \\
\hline ACCI + Se-cysteine & $14,7 \pm 0,78^{*}$ & $7,0 \pm 0,55^{*}$ \\
\hline ACCI + Se-methionine & $11,3 \pm 0,67^{*}$ & $5,5 \pm 0,47^{*}$ \\
\hline ACCI + selenoline & $8,9 \pm 0,38$ & $5,3 \pm 0,30^{*}$ \\
\hline
\end{tabular}

Note: ${ }^{*}-\mathrm{p} \leq 0.05$ in relation to the control

Thus, in the group of untreated animals, there was a significant decrease in the levels of HSP70 in the cytosol and mitochondria by $59 \%$ and $47 \%$ respectively, on the 4th day of the experiment. Administration of Se-cysteine, Se-methionine and Selenoline contributed to the normalization of its levels, which indicates their cytoprotective properties and the ability to prevent inhibition of expression of HSP70 genes in the neurons. Animals treated with Semethionine had the concentration of the HSP70 protein in the brain homogenate increased by 2.8 times, and with the use of Se-cysteine it amounted to 21.7 s.u./g, which is 3.4 times higher than in the control group. Therefore the data obtained indicate that the use of Se-cysteine produces statistically significant activation of HSP70 gene expression in neurons.

PCR studies detected a tendency to increase levels of mRNA HSP70 expression in all the experimental groups of animals treated with selenium-containing drugs by comparison with the control group on the $4^{\text {th }}$ day $(p<0.05)$. The most effective medication was Secysteine, and the least effective was Selenoline. This activity of Se-cysteine is associated with its antioxidant activity and the ability to regulate redox-dependent mechanisms of expression.

Table 3 - Expression of mRNA HSP70, , mRNA HIF-1, and mRNA HIF3 in the bran of animals with ACCI

\begin{tabular}{|l|l|l|l|}
\hline Group of animals & $\begin{array}{l}\text { MPHK HSP70, } \\
\text { y.e. }\end{array}$ & $\begin{array}{l}\text { MPHK HIF-1a, } \\
\text { y.e. }\end{array}$ & $\begin{array}{l}\text { MPHK HIF-3a, } \\
\text { y.e. }\end{array}$ \\
\hline False-operated & $1,0000 \pm 0,0117$ & $1,0000 \pm 0,2380$ & $1,0000 \pm 0,1144$ \\
\hline ACCI & $0,09761 \pm 0,0087$ & $0,12665 \pm 0,0721$ & $0,35432 \pm 0,05532$ \\
\hline ACCI + Se-cysteine & $0,8784 \pm 0,0023^{*}$ & $1,42235 \pm 0,0532^{*}$ & $1,17641 \pm 0,0412^{*}$ \\
\hline ACCI + Se-methionine & $0,6552 \pm 0,0011^{*}$ & $0,54551 \pm 0,0243^{*}$ & $0,48352 \pm 0,0511$ \\
\hline ACCI + selenoline & $0,2881 \pm 0,0031^{*}$ & $0,12778 \pm 0,0801$ & $0,38221 \pm 0,0314$ \\
\hline
\end{tabular}

Note: * - изменения достоверны по отношению к группе контроля $(\mathrm{p}<0,05)$

A comparative analysis of the protein levels and HSP70 expression on the 4th day of the post-occlusion period against the background of the therapy with selenium-containing drugs showed an increase in gene expression and intensification of protein synthesis, which indicates the mobilization of the mechanisms of endogenous neuroprotection. One of the most important functions of HSP70 is induction as well as extension of survival time of the stable form of HIF in animal models.

The hypoxia-inducible factors HIF-1 and HIF-3 play the role of transcription factors and regulate the expression of genes encoding the synthesis of proteins involved in the physiological response to hypoxia/ischemia [13-14]. It has been found that during hypoxia, the levels of HIF-1 $\alpha$ increase, mainly in the cytoplasm [14], whereas the levels of HIF-3 $\alpha$ increase mainly in the cell nucleus of the neuron [11, 13]. Both HIF isoforms interact with each other according to the principle of negative feedback under hypoxic conditions. 
Thus, the HIF- $1 \alpha$ protein can affect HIF- $3 \alpha$ gene expression, and the HIF- $3 \alpha$ protein competes with HIF-1 $\alpha$ when binding to HIF-1 $\beta$ subunits, and reduces the expression levels of the latter [2,11]. The HIFs are significant participants in the processes of neuroprotection and neuroplasticity under hypoxic conditions; they stimulate reparative processes in nervous tissue, increasing the pool of the free radical trapping agents and VEGF [4, 7]. HIF under hypoxic conditions increase the energy resources of the neuron, participating in the processes of metabolism of glucose and key glycolysis enzymes, thereby increasing ATP synthesis under conditions of energy deficiency [3]. Anti-apoptotic effects leading to a decrease in neuronal death in cerebral ischemia have been described [5]. HIF-1 can increase the levels of GSH in the brain of rats with experimental ACCI $[3,5]$.

Under conditions of intensification of reactions of oxidative, nitrosative stress and lack of energy sources in brain tissues, a decrease in HIF synthesis develops, which many researchers associate with the activation of the ubiquitin-independent pathway of degradation of oxidatively modified HIF- $1 \alpha$ and the suppression of its synthesis at the stage of translation under conditions of ATP deficiency [14]. The course of administration of the studied drugs for 4 days after CVA modeling led to an increase in the expression of mRNA HIF-1 $\alpha$ : Secysteine - by 11.2 times over the control $(p<0.05)$, Se-methionine - by 3.1 times over the control ( $\mathrm{p}<0.05)$, and Selenoline - by 1.1 times over the control $(\mathrm{p}>0.05)$. Only Se-cysteine statistically significantly increased $(p<0.05)$ the levels of HIF-3 $\alpha$ expression (by 3.6 times over the control).

The results obtained demonstrated that the administration of modulators of the glutathione system leaded to an increase in the expression of the HIF- $1 \alpha$ and HIF-3 $\alpha$ genes and could serve as a molecular marker of the activation of the mechanisms of endogenous neuroprotection under conditions of experimental cerebral ischemia.

\section{RESULTS AND DISCUSSION}

The family of HSP is induced in the cells of all living organisms in response to the action of numerous stress factors, such as heat shock, hypoxia, ischemia, metabolic disorders, viral infection, and administration of pharmacological agents [11]. A significant number of works have been devoted to the participation of the endogenous cytoprotective proteins HIF and HSP in the regulation of these processes; therefore, it is topical to use these proteins to increase the resistance of neuronal cells to hypoxia/ischemia. Many researchers express assumption of the ability of HSP70 to resist mitoptosis through the transport and folding of proteins in mitochondria; to hamper the processes of free radical protein damage; to limit the damaging influence of free radicals on mitochondrial membranes [5].

Besides, the compensatory mitochondrial-cytosolic shunts of energy production are activated due to the properties of HSPs to extend HIF survival time [14]. All of the above indicates the great importance of the expression and synthesis of HSPs in the implementation of compensatory-adaptive cellular reactions under conditions of oxidative stress. Another significant property of heat shock proteins described in the scientific literature is their regulatory effect on the processes of cell death $[1,5]$.

These effects of HSPs are most likely explained by the following: first, due to the ability of HSPs to limit the cytotoxic action of free radicals; secondly, due to the energotropic action, HSP70 under conditions of hypoxia may hamper the fall of mitochondrial membrane potential and the opening of the mitochondrial pore; and, finally, third, HSPs, according to some researchers, modulate the expression of the redox-sensitive transcription factors such as nuclear factor kappa B (NF-kB) and c-fos that is associated with their main biological function as the chaperone proteins.

A tandem of HSP-HIF proteins is a universal mechanism of neuronal protection against damage of different genesis. Considering the importance of HSPs in the processes of 
cytoprotection, the attention of scientists is focused on the possibility of using HSPs for the prevention and treatment of a number of neurodestructive diseases. A lack of HSP70 in GSH deficient neurons is apparently associated with overproduction of reactive oxygen species (ROS) and cytotoxic forms of nitric oxide, leading not only to modification (reversible and irreversible) of macromolecules, including HSP70 itself, but also can decrease gene expression of various mRNA by either inhibiting translation or directly causing degradation of the transcript [14].

Administration of Se-cysteine, Se-methionine and Selenoline to rats with CVA modeling revealed the ability of these drugs to activate HSP70-dependent mechanisms of endogenous neuroprotection, hamper the pathophysiologic processes of oxidative protein modification with following neurologic and cognitive disorders. The treated groups of animals had a decrease in mortality rate and reduction in neurological signs in comparison with the control. The most effective of the studied drugs was Se-cysteine. The effectiveness of Se-cysteine is based on its ability to positively influence on glutathione synthesis, regulate the expression of Se-glutathione peroxidase (Se-GPR), as well as the GSH-dependent mechanisms of endogenous neuroprotection.

Se-methionine is able to regulate the formation of carnitine, which plays the role of a "shuttle" in the formation of acetyl-CoA from fatty acids [9, 15]. Se-methionine has also properties a mitoprotector, preventing irreversible oxidation of SH-groups of proteins of cyclosporine A-dependent mitochondrial pore aimed at preserving the energy-producing function of these organelles in hypoxia/ischemia [15]. Se-methionine can also inhibit the activity of IL-1b receptors and the expression of the inducible NO synthase (iNOS) [7]. The selenium residue in brain tissues can modulate the affinity of glutamate receptors, in particular, NMDA receptors [2, 9].

This action of selenium is especially important under conditions of glutamate excitotoxicity, which occurs in hypoxia/ischemia and leads to an increase in the intracellular concentration of $\mathrm{Ca}^{2}+$, activation of NO-synthase, intensive formation of $\mathrm{NO}$ and peroxynitrite $\left(\mathrm{ONOO}^{-}\right)$, which is a direct cause of cell death. Decreasing hyperexcitability of glutamate receptors, selenium reduces the release of excitatory amino acids (glutamate and aspartate), thereby hampers the manifestations of glutamate excitotoxicity.

The significant antioxidant activity of Se-cysteine and Se-methionine is mediated by the presence of selenium in their structure, due to which the drugs have strong reducing properties and the ability to receive electrons from various reactive oxygen species. From the above, it follows that Se-cysteine, as well as Se-methionine, can be attributed to the group of antioxidants that are the free radical trapping agents [4]. These drugs transform free oxygen radicals into an inactive state, reactivate antioxidant enzymes, and contribute to more efficient use of the non-enzymatic antioxidant tocopherol. As a result, the structure and functions of neuronal cells remain undamaged.

The study of antioxidant modulation of HSP70-dependent endogenous mechanisms of brain neuroprotection with selenium-containing drugs revealed that administration of Selenoline, Se-cysteine and Se-methionine led to the activation of endogenous neuroprotection, therefore indicating the topicality of further study of these drugs on other models of pathological processes accompanied by the development of ischemia.

\section{REFERENCES}

1. Belenichev I. F., Bila Yu. V. Relationships between HSP70 concentrations, an active thiol-disulfide system and neurological disorders level in acute cerebral ischemia model. Bulletin of Problems in Biology and Medicine. 2017;1:86-91. URL : http://vpbm.com.ua/upload/2017-1/17.pdf 
2. Belenichev I.F., Cherny V.I., Nagornaya E.A., Pavlov S.V., Cherny T.V. et al [Neuroprotection and Neuroplasticity]. Kyiv: Logos, 2015. 510 p. Russian

3. Belenichev I.F., Gorbacheva S.V., A.V. Demchenko, Bukhtiyarova N.V. The thioldisulfide balance and the nitric oxide system in the brain tissue of rats' subjected to experimental acute impraiment of cerebral blood flow: the therapeutic effects of nootropic drugs. Neurochemical Journal. 2014;1(8): 24-27. doi: http:// DOI: 10.1134/S181971241401005X

4. Belenichev I.F., Mazur I.A., Abramov A.V., Kucherenko L.I., Bukhtiayarova N.V. The endothelium-protective effect of 3-methyl-1,2,4-triazolyl-5-thioacetate (S)-2,6diaminohexanic acid (lysinium): Effects on the expression of vascular endothelial growth factor (VEGF) and the characteristics of the endotheliocytes of the cerebral vessels of animals with cerebral ischemia. Neurochemical Journal. 2013;7. 296-302. doi: https://doi.org/10.1134/S181971241304003X

5. Belenichev I.F., Mazur, L.I. Kucherenko, Nagornaya E.A., Gornacheva S.V. et al. The Molecular and Ultrastructural Aspects of the Formation of Mitochondrial Dysfunction in the Modeling of Chronic Cerebral Ischemia: the Mitoprotective Effects of Angiolin. Neurochemical Journal. 2016;2(10).131-136. doi: http:// DOI: 10.1134/S1819712416010025

6. Belenichev I.F., Pavlov S.V., Bukhtiayarova N.V., Samura I.B., Egorov A.N., Semenov D.M. Expression of HSP70 in the Brain of Rats During Experimental Cerebral Ischemia Modeling and on the Background of Neuroprotection. Biological Markers and Guide Therapy 2017;1(4):105-111. doi:https://doi.org/10.12988/bmgt.2017.7911

7. Belenichev I., Ryzhenko V.P., Ryzhov A.A. Analysis of influence of Quantum Chemical Descriptors on NO-Scavenger Properties among Xantine Derivatives. Biological Markers and Guide Therapy. 2017. № 1. P.39-48. doi: http:// DOI: 10.12988/bmgt.2017.735.

8. Chekman I.S., Belenichev I.F., Nagornaya E.A., Gorchakova N.A., Bukhtiyarova N.V. et al. [Pre-clinical study of specific activity of potential endothelioprotective drugs. Methodological instructions]: http:/www.m-hikari.com/bmgt/bmgt2018/bmgt12018/p/belenichevBMGT1-2018.pdfKyiv: TOV Vidavnitstvo Yuston, 2016. 82 p. Ukrainian

9. Klimenko L.L., Skalny A.V., Turna A.A., Kuznetsova A.V., Senko O.V. et al. The role of selenium in the multivariate etiopathogenesis of ischemic stroke. The Trace Eliments in Medicine. 2015;16(4):28-35. doi: http:// DOI: 10.19112/2413-6174-2015-16-4-28-35

10. Nefodov A.A., Belenichev I. F., Nefodova E.A., Bukhtiyarova N.V., Levich N.V., Dronov S.N. Neuroprotective effect of citicoline and glucocorticoid combination under conditions of experimental demyelinating model of central nervous system. Journal of Neurobehavioral Sciences.2018;3:131-136. doi: http:// DOI : 10.5455/JNBS.1525619232

11. Radons J. The human HSP70 family of chaperones: where do we stand? J. Cell Stress Chaperones. 2016;21:379-404 [PMC free article] [PubMed doi: http:// doi: 10.1007/s12192-016-0676-6

12. Ryzhenko V. P., Ryzhov O.A., Belenichev I.F., Levich S.V. Study of dependence of xanthine derivatives NO-scavenger properties from energy descriptors. Biological Markers and Guided Therapy. 2018;1:37-46. doi: https://doi.org/10.12988/bmgt.2018.857

13. Sharp F.R., Zhan X, Liu DZ. Heat shock proteins in the brain: role of Hsp70, Hsp 
27, and HO-1 (Hsp32) and their therapeutic potential. Transl Stroke Res 2013;4(6):685-92. doi: http:// doi: 10.1007/s12975-013-0271-4

14. Sun, Y., He, W., \& Geng, L. Neuroprotective mechanism of HIF-1 $\alpha$ overexpression in the early stage of acute cerebral infarction in rats. Experimental and Therapeutic Medicine.2016;12(1):391-395. doi: 10.3892/ etm.2016.3288.

15. Weekly C.M., Harris H.H. Which form is that? The importance of selenium speciation and metabolism in the prevention and treatment of disease. Chem Soc Rev. 2013;42:.8870-94. doi: http:// DOI: 10.1039/c3cs60272a 